\title{
Can existing mobile apps support healthier food purchasing behaviour? Content analysis of nutrition content, behaviour change theory and user quality integration
}

\author{
Sarah-Jane Flaherty ${ }^{1, *}$, Mary McCarthy ${ }^{1,2}$, Alan Collins ${ }^{1,3}$ and Fionnuala McAuliffe ${ }^{1,4}$ \\ ${ }^{1}$ HRB Centre for Health and Diet Research, University College Cork, Cork, Republic of Ireland: ${ }^{2}$ Department \\ of Management \& Marketing, University College Cork, Cork, Republic of Ireland: ${ }^{3}$ Department of Food Business \\ \& Development, University College Cork, Cork, Republic of Ireland: ${ }^{4}$ UCD Perinatal Research Centre, School of \\ Medicine, University College Dublin, National Maternity Hospital, Dublin, Republic of Ireland
}

Submitted 22 December 2016: Final revision received 20 July 2017: Accepted 29 August 2017: First published online 30 0ctober 2017

\begin{abstract}
Objective: To assess the quality of nutrition content and the integration of user quality components and behaviour change theory relevant to food purchasing behaviour in a sample of existing mobile apps.

Design: Descriptive comparative analysis of eleven mobile apps comprising an assessment of their alignment with existing evidence on nutrition, behaviour change and user quality, and their potential ability to support healthier food purchasing behaviour.

Setting: Mobile apps freely available for public use in GoogePlay were assessed and scored according to agreed criteria to assess nutrition content quality and integration of behaviour change theory and user quality components.

Subjects: A sample of eleven mobile apps that met predefined inclusion criteria to ensure relevance and good quality.

Results: The quality of the nutrition content varied. Improvements to the accuracy and appropriateness of nutrition content are needed to ensure mobile apps support a healthy behaviour change process and are accessible to a wider population. There appears to be a narrow focus towards behaviour change with an overemphasis on behavioural outcomes and a small number of behaviour change techniques, which may limit effectiveness. A significant effort from the user was required to use the mobile apps appropriately which may negatively influence user acceptability and subsequent utilisation.

Conclusions: Existing mobile apps may offer a potentially effective approach to supporting healthier food purchasing behaviour but improvements in mobile app design are required to maximise their potential effectiveness. Engagement of mobile app users and nutrition professionals is recommended to support effective design.
\end{abstract}

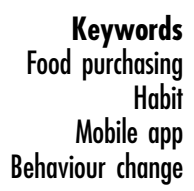

Unhealthy eating patterns are a known risk factor for a number of chronic diseases that contribute annually to premature death and disability globally ${ }^{(1,2)}$. Consequently, supporting healthier food behaviours is of key importance to population health. As the majority of household food expenditure takes place in the supermarket ${ }^{(3-5)}$, supporting healthier food purchasing behaviour is likely to have a positive impact on population dietary patterns. Healthier food purchasing behaviour may limit the availability of unhealthier foods in the home, thus acting as a controlling mechanism for consumers when cues towards competing goals and behaviours arise. However, consumers view healthy food purchasing as a difficult and effortful task ${ }^{(6)}$ and achieving long-term change has proved difficult. While both financial incentives and store-based interventions are associated with behavioural change, evidence indicates that their positive impact lasts only for the duration of the intervention ${ }^{(7,8)}$. Thus, alternative approaches are needed to achieve sustained change.

Grocery shopping is often viewed as a scripted routinised behaviour where consumers use individual scripts, or knowledge structures, to determine the behaviours which should be enacted in repeated events ${ }^{(9-11)}$. However, elements of food purchasing behaviour may also be viewed as habitual ${ }^{(12-15)}$, where consistent repetition of a behaviour in the presence of stable contextual 
cues increases the automaticity of that behaviour ${ }^{(16)}$. Subsequent habit performance is driven by these contextual cues such as time, people and places ${ }^{(15,17)}$. Traditional intervention approaches typically utilise educational measures to change individual knowledge levels and attitudes which fail to address the habitual elements that influence food purchasing behaviour ${ }^{(18,19)}$. Consequently, it is possible that the difficulty encountered in changing food purchasing behaviour may be due to the presence of habit and a lack of consideration of habit theory during intervention design. Future interventions should address both routine and habitual elements of food purchasing behaviour to improve the potential to achieve sustained behaviour change ${ }^{(20-22)}$.

Building on the cue-response relationship that drives habitual behaviour, van't Riet et $a l^{(22)}$ have outlined potential intervention strategies to support healthier food behaviours (Table 1). The first category, performance cue, focuses on the behavioural context and proposes adapting the cues which drive habit performance. The response category centres on changing the individual's response to the contextual cue through engagement of self-regulation processes. The final category, contingencies, outlines strategies that influence the reinforcement of habitual behaviour and can influence subsequent performance. This framework provides a useful theoretical basis to inform the development of future interventions to support healthier food purchasing behaviour.

Another important aspect of intervention development is identification of an appropriate mode for intervention delivery $^{(23)}$, with recent technological advances positioning mobile phones as a potentially effective approach ${ }^{(24-30)}$. High ownership levels mean there is potential to engage a significant proportion of the population ${ }^{(31)}$. Individuals display a strong attachment to their mobile phones, allowing participant engagement in relevant contexts $^{(32)}$; a key consideration in addressing habitual behaviours guided by contextual cues. One important recent technological advance is the development of mobile apps, which are software applications developed specifically for use on small, wireless computing devices such as smartphones and tablets. Mobile apps offer additional opportunities for individual engagement and support as they 'take advantage of computer capabilities as well as the power of networking ${ }^{\text {(33) }}$. Dietitians and nutritionists are incorporating mobile apps into their practice to a greater extent ${ }^{(34-36)}$. While more research is needed on their effectiveness in changing food behaviours, current evidence suggests there may be potential for a positive impact ${ }^{(37-40)}$. Existing mobile apps can support self-monitoring of dietary intake (e.g. weightmate), allow assessment of nutritional quality (e.g. FoodSwitch), or provide a grocery list creation function to support meal planning and purchasing behaviour (e.g. ShopShop). In relation to habitual behaviours, Stawarz et $a l .{ }^{(41)}$ proposed that mobile apps could support habit formation if designed correctly but did not comment on their potential effectiveness in changing habits. As mobile technology is continually advancing it is likely that newer features are being integrated which may address habitual elements of behaviour. Thus, mobile apps offer a novel approach to intervention delivery and warrant further consideration in relation to healthier food purchasing behaviour.

Despite potentially promising evidence, three potential issues have been raised. First, health interventions are typically more effective if based upon a valid theoretical framework ${ }^{(23,42)}$, but relevant theory is not always adequately utilised in mobile app design ${ }^{(41,43-45)}$. Second, the mobile app must be viewed as acceptable by the individual to ensure it is used for a sufficient period to support behaviour change. User quality components, such as engagement and functionality, have an important influence on acceptability ${ }^{(46-49)}$ but may also be inadequately integrated or done to the exclusion of theoretical content $^{(50,51)}$. The final consideration for dietary-related mobile apps is the quality of the nutrition information provided. Evidence suggests that the quality of healthrelated websites and mobile apps is varied ${ }^{(51-53)}$, with very little engagement of relevant health professionals in their $\operatorname{design}^{(51,53)}$ and an over-reliance on food composition databases that do not acknowledge individual differences or existing health conditions ${ }^{(35)}$. Incorrect nutrition advice can lead to unhealthy eating practices, with potential for negative health consequences ${ }^{(34)}$. It is essential that the nutrition content of a mobile app is based on sound information to ensure behaviour change is directed towards healthier food behaviours.

While mobile apps offer a novel approach for supporting healthier food purchasing behaviours, it is evident that a number of design issues need to be considered prior to their wider implementation in public health. Much research focuses on new technology development to

Table 1 Proposed strategies to change existing and create new habits (from van't Riet et al. ${ }^{(22)}$ )

\begin{tabular}{|c|c|c|c|c|c|}
\hline \multicolumn{3}{|c|}{ Creating new habits } & \multicolumn{3}{|c|}{ Changing existing habits } \\
\hline Performance cue & Response & Contingencies & Performance cue & Response & Contingencies \\
\hline $\begin{array}{l}\text { Personal strategies to } \\
\text { change contexts } \\
\text { Ecological interventions }\end{array}$ & $\begin{array}{l}\text { Implementation } \\
\text { intentions }\end{array}$ & $\begin{array}{l}\text { Reinforcement } \\
\text { management } \\
\text { Positive economic } \\
\text { incentives }\end{array}$ & $\begin{array}{l}\text { Ecological } \\
\text { interventions }\end{array}$ & $\begin{array}{l}\text { Exerting self-control } \\
\text { Vigilant monitoring } \\
\text { Counter-conditioning }\end{array}$ & $\begin{array}{l}\text { Self-imposed } \\
\text { penalties } \\
\text { Negative economic } \\
\text { incentives }\end{array}$ \\
\hline
\end{tabular}


Table 2 Inclusion and exclusion criteria for selection of mobile apps

\begin{tabular}{|c|c|}
\hline Inclusion criteria & Exclusion criteria \\
\hline $\begin{array}{l}\text { Must specifically aim to support healthier food } \\
\text { behaviours }\end{array}$ & $\begin{array}{l}\text { Targeted to specific population group (specific age group, specific } \\
\text { health condition or dietary requirement) }\end{array}$ \\
\hline English language & Focus on eating out \\
\hline $\begin{array}{l}\text { Minimum 3-star rating and at least } 50 \text { user rating } \\
\text { reviews completed in GooglePlay }\end{array}$ & $\begin{array}{l}\text { Database only (foods, recipes, information) } \\
\text { Requires subscription to access specific programme }\end{array}$ \\
\hline $\begin{array}{l}\text { Free: some in-app purchases can be available but } \\
\text { main app functions are free }\end{array}$ & $\begin{array}{l}\text { Tracking app only (food intake, weight) } \\
\text { Focus on sports nutrition or supplement use }\end{array}$ \\
\hline Available on GooglePlay and iTunes & Online shop \\
\hline $\begin{array}{l}\text { Available for public use in Ireland } \\
\text { For use on mobile phone (not tablet only) }\end{array}$ & Game \\
\hline
\end{tabular}

address such a problem, but Hingle and Patrick ${ }^{(47)}$ emphasise the need to utilise existing resources. Consequently, it is important to assess the potential of existing mobile apps to support healthier food purchasing behaviour. To date, no assessment of existing mobile apps has been made in relation to food purchasing behaviour focusing on behaviour change, user quality and nutrition content. Given the important influence that food purchasing behaviour has on subsequent dietary patterns and the potential effectiveness of mobile apps to support behaviour change, there is a need to further explore the potential role of existing mobile apps. Consequently, the aim of the present study was to assess the quality of nutrition content and the integration of user quality components and behaviour change theory relevant to food purchasing behaviour in a sample of existing mobile apps.

\section{Methods}

\section{Study design}

The study design involved a descriptive comparative analysis of a sample of eleven mobile apps, comprising an assessment of their alignment with evidence on nutrition, behaviour change and user quality, and their potential ability to support healthier food purchasing behaviour.

\section{Sample}

Due to the large number of dietary-related mobile apps available in GooglePlay ${ }^{(54)}$, it is not feasible to assess all available mobile apps. Instead, searches of GooglePlay in the Republic of Ireland were conducted to identify a sample of mobile apps that would most likely include mobile apps of good quality and of relevance to food purchasing behaviour. GooglePlay was chosen as it was the largest mobile application store and reported the most downloads at the time of the search ${ }^{(55)}$

In stage one of the review process, six different searches were conducted in GooglePlay using search terms aimed to maximise the relevance to food purchasing behaviour: 'healthy eating', 'healthy diet', 'healthy food', 'healthy shop', 'healthy food shop' and 'healthy food shopping'.
The top 100 returns for each search were included in the initial sample. The top 200 mobile apps in the health and fitness category of GooglePlay were also included. The larger number was included from this category as it is less specific than the search terms. Any duplicates were removed. In stage two, each mobile app in the initial sample was assessed according to predefined exclusion and inclusion criteria (Table 2). Development of these criteria was informed by relevant literature and specific study requirements and were agreed in advance by the authors. Mobile app titles and descriptions were reviewed to assess relevance and mobile apps were excluded if they did not meet the required criteria. All remaining mobile apps were downloaded and briefly reviewed and subsequently excluded if they did not meet the required criteria (stage three). A subset of mobile apps was reviewed by co-authors to confirm the applicability of the inclusion and exclusion criteria. For marginal cases, the team reviewed the mobile app and an agreement was reached on its inclusion. The mobile app name, developer and reason for exclusion were recorded for all excluded mobile apps. All remaining mobile apps were included in the final sample and underwent further assessment (stage four). The name, developer, average rating in GooglePlay, total number of ratings and the number of installs were recorded.

\section{Assessment criteria development}

The final sample of mobile apps was assessed and scored according to specific criteria which were agreed in advance by all authors. Details on the development of the assessment criteria and relevant scoring system are outlined below.

\section{Nutrition content}

The quality of the nutrition information provided in each mobile app was assessed by a qualified nutritionist in comparison to the dietary guidelines for the Republic of Ireland $^{(56,57)}$, and scored either 0 or 1 . Mobile apps were given a score of 0 if any information did not adhere to these guidelines and was not based upon valid scientific evidence. The reasons for a mobile app achieving a score of 0 were noted. The content of social forums, in which 
users could communicate with each other, was briefly reviewed to assess the type of nutrition information being shared and confirm the presence of a forum moderator. This content did not contribute to the quality score as it was not feasible to review all such content, but notes were kept for each mobile app and analysed as part of the subjective assessments, as detailed below.

\section{Behaviour change theory}

The framework proposed by van't Riet et al. ${ }^{(22)}$ (Table 1) informed the development of the behaviour change theory assessment criteria to ensure techniques that address both routine and habitual elements of food purchasing behaviour were examined. Behaviour change techniques $(\mathrm{BCT})^{(58)}$ were assigned to each strategy based on the descriptions provided by van't Riet et al. ${ }^{(22)}$. BCT are 'observable, replicable, and irreducible component[s] of an intervention designed to alter or redirect causal processes that regulate behaviour ${ }^{\text {(58) }}$ and provide a more informational and rigorous coding tool than previously used theory-based instruments ${ }^{(59)}$. The final set consisted of forty-eight BCT. A score of 1 was given for each technique observed in the mobile app, giving a potential total score of 48 for behaviour change theory.

\section{User quality}

The Mobile App Rating Scale (MARS) ${ }^{(60)}$ was used to assess mobile app quality. MARS is an objective measure for rating the quality of mobile health apps by assessing specific features shown to influence user interaction and mobile quality. Nineteen items are assessed across four different categories: engagement, functionality, aesthetics and information. All items within each category are measured on a 5-point scale with a higher score representing higher quality. A mean category score and a mean total quality score were calculated for each mobile app.

\section{Subjective assessment}

The primary author undertook a qualitative subjective assessment of each mobile app to ensure those features not assessed elsewhere were captured, such as offline accessibility, and to provide further insight to quantitative assessment scoring. An assessment of features was made based on those highlighted in the relevant literature.

\section{Assessment procedure}

The final sample of mobile apps ( $n$ 11) that met the inclusion criteria were downloaded for four days and scored against the assessment criteria by the primary author, a qualified nutritionist. A standard user profile was developed in advance of the assessment process and used during mobile app registration, where required. Data extraction, mobile app assessment and analysis were conducted between July and October 2016.

\section{Inter-rater reliability}

For the purpose of reliability, mobile apps were independently scored by a second reviewer. Scoring of BCT and user quality was undertaken by a colleague with experience in the area of food behaviour. Scoring of the nutrition content was undertaken by a registered dietitian. The assessment criteria were discussed with each reviewer to ensure an agreed understanding and clarify any ambiguous items. A pilot scoring exercise was conducted on two mobile apps, not included in the final sample, to assess initial understanding and inter-rating agreement. Disagreements were discussed and a consensus of understanding agreed prior to secondary review of the final sample of mobile apps. Upon completion of secondary coding, disagreements were resolved by discussion, and a final score was jointly agreed.

\section{Analyses}

The internal consistency of the MARS was calculated using Cronbach's alpha ${ }^{(61)}$. Krippendorff's alpha was used to evaluate inter-rater reliability ${ }^{(62)}$. The total and median number of BCT integrated into the eleven selected mobile apps were calculated. The median was calculated for the overall MARS score, each of the MARS subscale scores and the nutrition content score. Spearman's correlations were used to explore the relationships between behaviour change theory, user quality components and average user ratings provided in GooglePlay. All tests were carried out using the statistical software package IBM SPSS Statistics version 24 with significance level set at $P<0 \cdot 05$. Content analysis, using NVivo version 11, was performed on the qualitative subjective assessment records in line with the approach proposed by Forman and Damschroder ${ }^{(63)}$.

\section{Results}

\section{Mobile app selection}

Figure 1 outlines the selection process for mobile apps, highlighting the reasons for exclusion at each stage. The most common reason for exclusion was lack of a specific aim to support healthier food behaviours ( $n$ 329; 61\%) with many focusing solely on physical activity ( $n$ 124). Table 3 outlines the key characteristics of the mobile apps selected for inclusion in the final sample.

\section{Integration of behaviour change techniques}

The reliability estimate for BCT coding was good (0.88). There was a distinct lack of focus on food purchasing behaviour in the selected mobile apps, with most focusing on behavioural outcomes such as weight management. Only one mobile app permitted goal setting directly related to food purchasing behaviour, with the majority of goal setting focusing on weight loss or energy intake. The most common feature directly related to food purchasing 


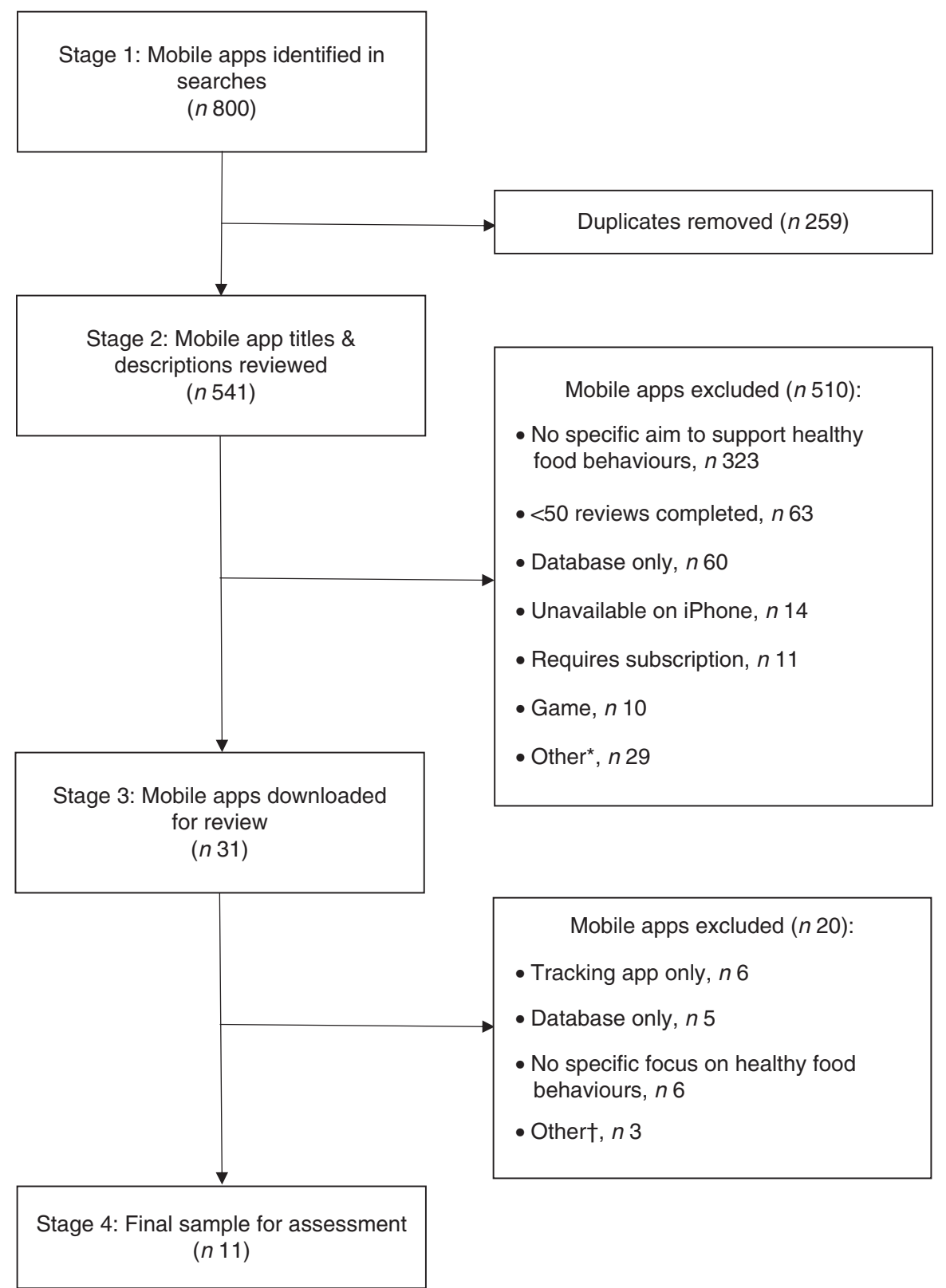

Fig. 1 Flowchart of the selection process for mobile apps. ${ }^{*}$ Other reasons for exclusion: online shop ( $n$ 9); focus on specific group $(n 5)$; main features not free ( $n 4)$; rating $<3$ stars $(n 3)$; not available in English $(n 3)$; tracking mobile app only $(n 3)$; focus on eating out $(n 1)$; online magazine $(n 1)$. †Other reasons for exclusion: main features not free $(n 2)$; error present in download $(n 1)$

was the provision of a grocery list based on recommended meal plans, which may support behaviour change through conservation of mental resources; this feature was incorporated into four of the eleven mobile apps. The median number of BCT recorded in a mobile app was three and all selected mobile apps incorporated at least two techniques (Table 3). Table 4 outlines the BCT integrated in the selected mobile apps. The most popular techniques incorporated were goal setting (outcome of behaviour; $n$ 11), self-monitoring of outcome(s) of behaviour ( $n$ 11), conserving mental resources ( $n$ 5) and behaviour substitution ( $n$ 5). The majority of BCT integrated focused on influencing the individual's response or the performance cue (73\%; Table 1). Thirty-three of the forty-eight BCT in the assessment criteria were not integrated into any mobile app.

\section{Quality of nutrition content}

The reliability estimate for nutrition content quality was good $(0 \cdot 80)$. The median nutrition score was 1 . Four of the eleven selected mobile apps were scored 0 (Table 3). Information in these mobile apps focused on fad diets with no scientific basis, such as detox diets, and much of the nutrition information was provided by unqualified individuals, such as bloggers or brand representatives. While the majority of mobile apps attained a score of 1 and provided evidenced-based information, improvements are still 
Table 3 Key characteristics of mobile apps selected for inclusion in the final sample

\begin{tabular}{|c|c|c|c|c|c|c|c|c|c|c|c|c|}
\hline & $\begin{array}{l}\text { Mobile } \\
\text { App } 1\end{array}$ & $\begin{array}{l}\text { Mobile } \\
\text { App } 2\end{array}$ & $\begin{array}{l}\text { Mobile } \\
\text { App } 3\end{array}$ & $\begin{array}{l}\text { Mobile } \\
\text { App } 4\end{array}$ & $\begin{array}{l}\text { Mobile } \\
\text { App } 5\end{array}$ & $\begin{array}{l}\text { Mobile } \\
\text { App } 6\end{array}$ & $\begin{array}{l}\text { Mobile } \\
\text { App } 7\end{array}$ & $\begin{array}{l}\text { Mobile } \\
\text { App } 8\end{array}$ & $\begin{array}{l}\text { Mobile } \\
\text { App } 9\end{array}$ & $\begin{array}{l}\text { Mobile } \\
\text { App } 10\end{array}$ & $\begin{array}{c}\text { Mobile } \\
\text { App } 11\end{array}$ & Median \\
\hline Nutrition content $(0 / 1)$ & 0 & 1 & 1 & 0 & 0 & 1 & 0 & 1 & 1 & 1 & 1 & 1 \\
\hline $\begin{array}{l}\text { Behaviour change theory } \\
\text { (count) }\end{array}$ & 2 & 2 & 3 & 5 & 4 & 2 & 2 & 6 & 14 & 2 & 5 & 3 \\
\hline Overall user quality (scale: $1-5$ ) & 3.8 & $4 \cdot 1$ & $4 \cdot 1$ & 3.4 & $3 \cdot 3$ & 3.9 & $3 \cdot 3$ & 3.7 & 4.0 & 3.9 & 3.6 & $3 \cdot 8$ \\
\hline Engagement (scale: $1-5$ ) & 3.4 & 3.8 & $3 \cdot 8$ & $2 \cdot 8$ & 3.0 & $3 \cdot 8$ & 3.4 & 3.2 & 4.0 & 3.6 & 3.4 & 3.4 \\
\hline Functionality (scale: $1-5$ ) & 3.5 & 4.5 & 4.5 & 4.0 & 3.5 & 4.0 & 3.5 & $3 \cdot 8$ & 4.0 & 4.0 & 3.5 & 4.0 \\
\hline Aesthetics (scale: $1-5$ ) & 4.7 & 4.7 & $4 \cdot 3$ & 3.7 & 3.7 & 4.0 & 3.0 & 4.0 & 4.0 & 4.3 & 3.7 & 4.0 \\
\hline Information (scale: $1-5$ ) & 3.7 & 3.5 & 3.9 & $3 \cdot 0$ & 3.0 & $3 \cdot 8$ & $3 \cdot 3$ & 3.7 & 4.0 & $3 \cdot 7$ & 4.0 & 3.7 \\
\hline Available offline & Yes & No & Yes & Yes & Yes & No & Yes & Yes & Yes & No & No & \\
\hline Installs (thousands) & $10000-50000$ & $1000-5000$ & $1000-5000$ & $1000-5000$ & $100-500$ & $10-50$ & $5000-10000$ & $50-100$ & $10000-50000$ & $100-500$ & $10-50$ & \\
\hline Rating in GooglePlay & 4.6 & 4.4 & 4.4 & $4 \cdot 2$ & 4.2 & 3.9 & 4.4 & 3.9 & $4 \cdot 3$ & 4.5 & 3.2 & \\
\hline Total no. of ratings & 1347192 & 19478 & 16454 & 30364 & 1920 & 77 & 53229 & 516 & 121369 & 5282 & 52 & \\
\hline
\end{tabular}

Table 4 Behaviour change techniques integrated into the selected mobile apps

\begin{tabular}{|c|c|c|c|c|c|c|c|c|c|c|c|c|}
\hline $\begin{array}{l}\text { Change strategy (van't } \\
\text { Riet et al. }{ }^{(22)} \text { ) }\end{array}$ & Behaviour change technique & $\begin{array}{l}\text { Mobile } \\
\text { App } 1\end{array}$ & $\begin{array}{l}\text { Mobile } \\
\text { App } 2\end{array}$ & $\begin{array}{l}\text { Mobile } \\
\text { App } 3\end{array}$ & $\begin{array}{l}\text { Mobile } \\
\text { App } 4\end{array}$ & $\begin{array}{l}\text { Mobile } \\
\text { App } 5\end{array}$ & $\begin{array}{l}\text { Mobile } \\
\text { App } 6\end{array}$ & $\begin{array}{l}\text { Mobile } \\
\text { App } 7\end{array}$ & $\begin{array}{l}\text { Mobile } \\
\text { App } 8\end{array}$ & $\begin{array}{l}\text { Mobile } \\
\text { App } 9\end{array}$ & $\begin{array}{l}\text { Mobile } \\
\text { App } 10\end{array}$ & $\begin{array}{l}\text { Mobile } \\
\text { App } 11\end{array}$ \\
\hline \multirow[t]{5}{*}{ Individual response } & Goal setting (outcome) & $\checkmark$ & $\checkmark$ & $\checkmark$ & $\checkmark$ & $\checkmark$ & $\checkmark$ & $\checkmark$ & $\checkmark$ & $\checkmark$ & $\checkmark$ & $\checkmark$ \\
\hline & $\begin{array}{l}\text { Self-monitoring of outcome(s) of } \\
\text { behaviour }\end{array}$ & $\checkmark$ & $\checkmark$ & $\checkmark$ & $\checkmark$ & $\checkmark$ & $\checkmark$ & $\checkmark$ & $\checkmark$ & $\checkmark$ & $\checkmark$ & $\checkmark$ \\
\hline & $\begin{array}{l}\text { Comparative imagining of future } \\
\text { outcomes }\end{array}$ & & & & & & & & & $\checkmark$ & & \\
\hline & Information about antecedents & & & & & & & & & $\checkmark$ & & \\
\hline & Behaviour substitution & & & & $\checkmark$ & $\checkmark$ & & & $\checkmark$ & $\checkmark$ & & $\checkmark$ \\
\hline \multirow[t]{6}{*}{ Performance cue } & Conserving mental resources & & & $\checkmark$ & $\checkmark$ & $\checkmark$ & & & $\checkmark$ & & & $\checkmark$ \\
\hline & Prompts/cues & & & & & & & & $\checkmark$ & $\checkmark$ & & \\
\hline & Distraction & & & & & & & & & $\checkmark$ & & \\
\hline & Restructuring the physical environment & & & & & & & & & $\checkmark$ & & \\
\hline & Restructuring the social environment & & & & & & & & & $\checkmark$ & & \\
\hline & $\begin{array}{l}\text { Avoidance/reducing exposure to cues } \\
\text { for the behaviour }\end{array}$ & & & & $\checkmark$ & & & & & $\checkmark$ & & \\
\hline Contingencies & Social support (unspecified) & & & & & & & & $\checkmark$ & $\checkmark$ & & $\checkmark$ \\
\hline & Information about others' approval & & & & & & & & & $\checkmark$ & & \\
\hline & Non-specific reward & & & & & & & & & $\checkmark$ & & \\
\hline & Non-specific incentive & & & & & & & & & $\checkmark$ & & \\
\hline
\end{tabular}


required in relation to the quantity of information provided in some of the mobile apps. For example, feedback was often provided on dietary intake, such as highlighting that saturated fat consumption was higher than recommended levels. However, no information was provided subsequently on the foods consumed that contributed to this high intake. The setting of dietary goals was also an area where information was lacking. Many of the mobile apps allowed users to set dietary goals, such as energy or fat intake, but little guidance was given on appropriate goal setting, which may lead to unhealthier dietary practices. The nutrition information shared in the social forums generally focused on promoting branded diet programmes, supplements or weight-loss products, and recipe sharing. A forum moderator was apparent in only one of the mobile apps and provided evidenced-based nutrition information to users and corrected any misinformation being shared. The involvement of registered nutrition professionals in the development of the mobile apps was unclear and were cited as sources of information in only four mobile apps.

\section{Integration of user quality components}

The MARS total score had high internal consistency (0.87) and demonstrated good inter-rater reliability (0.84). Table 3 outlines the median overall MARS score and scores for each subscale. The lowest score was seen for engagement. Customisation is a key element of engagement and customisation options differed between mobile apps. While some offered users the option to customise meal plans to suit preferences or set personally relevant goals, others provided limited personalised options. The relationship between integration of user quality components, as rated by MARS, and the average rating provided by users in GooglePlay was examined and no correlation was evident $(\rho=0 \cdot 32 ; P=0 \cdot 34)$.

\section{Relationship between behaviour change theory integration and user quality components}

Using MARS as a measure of user quality, no significant relationship was identified between integration of behaviour change theory and user quality $(\rho=-0 \cdot 114$, $P=0.67$ ). The average rating provided by users in GooglePlay is another measure of user quality and no significant relationship was seen with integration of behaviour change theory $(\rho=-0.58 ; P=0.06)$.

\section{Subjective assessment}

The subjective assessment analysis highlighted a number of issues. Seven of the eleven mobile apps were accessible offline (Table 3), although the quantity of offline content varied. This may influence the usability of the mobile app in the supermarket where Internet access may be limited. Reviewers noted that considerable time and effort were required to utilise many of the mobile apps, especially those focusing on self-monitoring of food consumption. There was a distinct lack of guidance on how to use the mobile apps and the user was required to navigate through the different sections to learn of its functions. It is possible that users may miss important features or use them inappropriately without instructions.

\section{Discussion}

Alignment of behaviour change theory, sound nutrition information and adequate user quality is proposed to be a necessary condition for successful behaviour change. The present study is the first time that existing mobile apps have been analysed in relation to these components, focusing specifically on healthier food purchasing behaviour. While findings highlight a number of positive characteristics that may facilitate behaviour change, there are many opportunities for improvement.

\section{Mobile apps and bealtby food purchasing behaviour}

It is evident that there is a distinct lack of focus on food purchasing behaviour in existing mobile apps, with most directed at behavioural outcomes such as weight management. This is surprising, and disappointing, given that food purchasing represents a key step in the food choice decision-making process ${ }^{(3-5)}$. An overemphasis on behavioural outcomes may negatively influence the potential to effect change because setting interim learning goals is shown to be more effective than focusing solely on outcome goals, although supporting progression to achieve a behavioural outcome is most effective ${ }^{(64,65)}$. On a positive note, BCT were integrated into all mobile apps although the average of three techniques was lower than the average of ten reported in a similar study ${ }^{(66)}$. This may be due to the difference in behavioural focus, with the latter focusing on multiple behaviours, including physical activity and food behaviours, rather than a single behaviour such as food purchasing behaviour. It is possible that existing mobile apps are better developed to address wider behavioural outcomes rather than specific food behaviours. Future development should give greater attention to food purchasing behaviour and support interim goal setting and subsequent progression to maximise potential effectiveness.

Analysis of the integrated BCT provided some interesting findings. The most popular techniques, goal setting and self-monitoring of behavioural outcomes, were similar to those found in other reviews ${ }^{(43,66-69)}$. An important finding in the context of food purchasing behaviour is that the third most popular technique was conserving mental resources, which focuses on addressing the performance cue. As contextual cues play a key role in directing the habitual elements of food purchasing behaviour ${ }^{(15-17,55)}$, it is a promising development that such techniques are being integrated. Only a limited number of the relevant BCT were integrated into any of the mobile apps with a 
particular focus on influencing the individual's response or the performance cue; this also reflects findings from elsewhere ${ }^{(68,70)}$. Such approaches may not be wholly effective for all users and techniques addressing behavioural reinforcement may also be appropriate ${ }^{(70)}$. Similar to other reviews, the extent of integration varied from two to fourteen techniques ${ }^{(43,70,71)}$. As Webb et al. ${ }^{(72)}$ found that Internet-based interventions had a greater effect if they incorporated a greater number of techniques, it may be a positive progression that a greater number of techniques are being integrated. However, it is unknown if this is valid for mobile apps and it is possible that integration of too many may complicate use of the mobile app and negatively influence the user experience. Future research should explore the integration of additional and alternative BCT to ensure the complex nature of changing food purchasing behaviour is addressed. The subsequent impact on the user experience is an important consideration, with a need to identify the optimal level required to effect change with minimal negative impact on acceptability.

From an initial sample of 541, only eleven mobile apps were eligible for inclusion in the final sample. While inclusion criteria aimed to identify those rated as higher quality and of greater relevance to healthier food purchasing behaviour, it was unexpected that so few matched the criteria. The most common reason for exclusion was a lack of focus on healthy food behaviours despite the use of specific search terms on food and healthy eating. As consumers may use the name as a cue of its relevance to their goals, it may prove challenging to identify an appropriate mobile app and will require time and effort. There is a need to examine how consumers select mobile apps and where information on effectiveness and relevance could be shared.

\section{Quality of nutrition content}

Nutrition content quality was good, with many citing valid evidence sources or engaging a nutrition professional to provide information. However, despite inclusion criteria to identify mobile apps of higher quality, four of the eleven mobile apps provided nutrition information that was inadequate. All of these achieved a user rating score $>4$ in GooglePlay, suggesting they are viewed as being of good quality by users. Indeed, the high rating assigned to the mobile app may be a cue used by consumers to inform their decision on which are likely to be most effective. It is important to understand the cues that consumers use to assess mobile app quality to ensure users are directed towards those based upon valid scientific evidence, to reduce potential negative outcomes. As previously discussed, little instruction was offered to users of the mobile apps included in the present review. Consequently, it is likely that a reasonable standard of nutrition knowledge is required for their effective use. Expecting users to set weight loss or energy goals in the absence of relevant guidance is inappropriate and may lead to inappropriate goal setting, potentially resulting in unhealthy dietary practices ${ }^{(73,74)}$. Similar criticisms have been raised elsewhere $^{(68,73)}$ and highlight the need for mobile apps to facilitate the building of nutrition knowledge and skills rather than work on the assumption that they are present. Furthermore, allowing users to share information in social forums may be a useful means of offering social support, but in the absence of a forum moderator inaccurate nutrition information may be shared and contribute to unhealthier dietary behaviours. There is a clear need to engage nutrition professionals at all stages of design and delivery to ensure content is accurate and appropriate to support healthy behaviour change ${ }^{(73,75)}$.

\section{Integration of user quality components}

The selected mobile apps were of good user quality, in line with similar reviews ${ }^{(66,68)}$, although there are still areas for improvement especially in relation to engagement and information. As outlined previously, some mobile apps provided limited customisable options which may reduce their usefulness for some. Mass customisation, the ability for consumers to tailor a product to their specific needs, has become a popular marketing strategy in recent decades in an attempt to better meet consumer needs ${ }^{(76)}$. While this approach can improve the user experience, it may also increase user burden which may impact negatively on the user experience ${ }^{(76-78)}$. A staged approach to customisation may alleviate some of this burden while still allowing for personalisation ${ }^{(79)}$. User engagement is required to identify optimal levels of customisation to meet their needs and support a positive experience ${ }^{(77)}$. An important critique was the time and effort required to use the mobile apps adequately. Such a high level of involvement requires high user motivation which may not be realistic and may negatively impact on the user experience and continued use because motivation and time availability fluctuate over time. There is a need to explore alternative, less burdensome options for self-monitoring to improve the quality of the user experience.

It is important to highlight that no significant relationship was seen between the MARS score for user quality and the average user rating in GooglePlay, although the small sample size upon which this is based must be acknowledged. Azar et al. ${ }^{(71)}$ reported similar results, although they did not use MARS as a measure of quality. This discrepancy may be due to differences between users and researchers in the assessment of quality, such as nutrition information. The quality of nutrition information was considered inadequate in some mobile apps, contributing to a lower information quality score. However, these mobile apps were rated highly by users in GooglePlay. It is possible that the nutrition information was viewed positively by users as it was congruent with their existing beliefs, but objectively such information is of a lower standard. Furthermore, measures such as user trust, ability and confidence are shown to be important ${ }^{(26,46,80)}$ and it is 
possible that MARS does not currently capture these factors adequately. User engagement at all stages of development is important to understand the factors which influence the user experience and mobile app acceptability ${ }^{(81)}$.

\section{Limitations}

The present study was not a review of all mobile apps currently available and it is possible that some relevant mobile apps may be missing. It is estimated that greater than 165000 health and fitness mobile apps are available and it is not feasible to review all adequately. Consequently, the aim was to identify and highlight some of the issues present in existing mobile apps in relation to food purchasing behaviour to subsequently inform mobile app and intervention design.

Our selection was restricted to mobile apps publicly available in the Republic of Ireland and it is possible that relevant mobile apps are available elsewhere. For example, the FoodSwitch mobile app ${ }^{(82)}$, which aims to provide easyto-understand nutritional information on food purchasing choices and recommend healthier alternatives, is currently unavailable in the Republic of Ireland and could not be included in our review. Additional relevant mobile apps may be available elsewhere which address some of the issues highlighted herein. Engagement with the relevant organisations is recommended to support their wider introduction.

The present review was undertaken by health and nutrition researchers who are not likely to be the target group for a mobile dietary intervention. Consequently, their scoring of the mobile apps, while displaying good reliability, may not correspond with scoring undertaken by an intended user group. While this analysis highlights issues from the perspective of nutrition and health professionals, there is a need to explore the importance of these components with intended user groups and assess their influence on mobile app acceptability and adoption.

\section{Conclusions}

The present study is the first to assess nutrition information quality and the integration of behaviour change theory and user quality in existing mobile apps in relation to food purchasing behaviour. It illustrates that supporting healthier food purchasing behaviour is often not a core component of existing mobile apps. Despite this, existing mobile apps do offer the potential to effect change in food purchasing behaviour and design improvements may improve such potential effectiveness. Furthermore, engagement of nutrition professionals in mobile app design is necessary to address potential issues relating to accuracy and appropriateness, to ensure mobile apps support a healthy behaviour change process. The apparent narrow focus towards behaviour change with an overemphasis on behavioural outcomes and a limited number of BCT must be addressed to ensure they are relevant for a wider user group.
The integration of alternative techniques may be beneficial although consideration must be given to the complexity this may add and their potential impact on the user experience. User engagement is crucial to gain a better insight into these issues and inform future development.

\section{Acknowledgements}

Acknowledgements: The authors wish to thank Jessica Finn, Aoife Harvey, Leah Hegarty and Elaine Walsh for their support during the mobile app assessment stage. Financial support: This work was supported by the HRB Centre for Health \& Diet Research (grant reference HRC/ 2014/13) and conducted as part of the SPHeRE Programme (grant number SPHeRE/2013/1). The funders had no role in the design, analysis or writing of this article. Conflict of interest: The authors declare that there are no conflicts of interest. Authorship: S-J.F., M.McC., A.C. and F.McA. worked on the study design and methods. S-J.F. was responsible for data collection and analysis and M.McC. and A.C. supervised analysis. S-J.F. wrote the paper and all authors provided feedback and approved the final manuscript. Ethics of human subject participation: Not applicable.

\section{References}

1. Institute for Health Metrics and Evaluation (2013) The Global Burden of Disease: Generating Evidence, Guiding Policy. Seattle, WA: Institute for Health Metrics and Evaluation.

2. World Health Organization (2003) Diet, Nutrition and the Prevention of Chronic Diseases. Report of a Joint WHO/FAO Expert Consultation. WHO Technical Report Series no. 916. Geneva: WHO.

3. Bord Bia (2015) PERIscope2015: Irish E British Consumers and their Food. Dublin: Bord Bia.

4. Department for Environment, Food and Rural Affairs (2015) Family Food. York: DEFRA.

5. US Department of Agriculture (2014) ERS Food Expenditure Series: Table 14. Washington, DC: USDA.

6. O'Brien MC, McConnon A, Hollywood LE et al. (2015) Let's talk about health: shoppers' discourse regarding health while food shopping. Public Health Nutr 18, 1001-1010.

7. Liberato S, Bailie R \& Brimblecombe J (2014) Nutrition interventions at point-of-sale to encourage healthier food purchasing: a systematic review. BMC Public Health 14, 919.

8. Roe L, Hunt P, Bradshaw H et al. (1997) Health Promotion Interventions to Promote Healthy Eating in the General Population: A Review. London: Health Education Authority.

9. Abelson RP (1981) Psychological status of the script concept. Am Psychol 36, 715-729.

10. Thomas A \& Garland R (2004) Grocery shopping: list and non-list usage. Market Intell Plann 22, 623-635.

11. Iyer ES \& Ahlawat SS (1987) Deviations from a shopping plan: when and why do consumers not buy items as planned. Adv Consum Res 14, 246-250.

12. Bettman JR, Johnson EJ \& Payne JW (1991) Consumer decision making. In Handbook of Consumer Behavior, pp. 50-84 [TS Robertson and HH Kassarjian, editors]. Englewood Cliffs, NJ: Prentice-Hall. 
13. Ji MF \& Wood W (2007) Purchase and consumption habits: not necessarily what you intend. J Consum Psychol 17, 261-276.

14. Strack F, Werth L \& Deutsch R (2006) Reflective and impulsive determinants of consumer behavior. J Consum Psychol 16, 205-216.

15. Wood W \& Neal DT (2009) The habitual consumer. J Consum Psychol 19, 579-592.

16. Lally P \& Gardner B (2013) Promoting habit formation. Health Psychol Rev 7, Suppl. 1, S137-S158.

17. Wood W, Tam L \& Witt MG (2005) Changing circumstances, disrupting habits. J Pers Soc Psychol 88, 918.

18. Verplanken B \& Wood W (2006) Interventions to break and create consumer habits. J Public Policy Mark 25, 90-103.

19. Webb TL \& Sheeran P (2006) Does changing behavioral intentions engender behavior change? A meta-analysis of the experimental evidence. Psychol Bull 132, 249-268.

20. Gardner B, Lally P \& Wardle J (2012) Making health habitual: the psychology of 'habit-formation' and general practice. BrJ Gen Pract 62, 664-666.

21. Lally P, Chipperfield A \& Wardle J (2008) Healthy habits: efficacy of simple advice on weight control based on a habit-formation model. Int J Obes (Lond) 32, 700-707.

22. van't Riet J, Sijtsema SJ, Dagevos H et al. (2011) The importance of habits in eating behaviour. An overview and recommendations for future research. Appetite $\mathbf{5 7}$, 585-596.

23. Craig P, Dieppe P, Macintyre S et al. (2008) Developing and evaluating complex interventions: the new Medical Research Council guidance. BMJ 337, a1655.

24. Afshin A, Babalola D, Mclean M et al. (2016) Information technology and lifestyle: a systematic evaluation of internet and mobile interventions for improving diet, physical activity, obesity, tobacco, and alcohol use. J Am Heart Assoc 5, $\mathrm{e} 003058$.

25. Free C, Phillips G, Galli L et al. (2013) The effectiveness of mobile-health technology-based health behaviour change or disease management interventions for health care consumers: a systematic review. PLOS Med 10, e1001362.

26. Lowe B, Fraser I \& Souza-Monteiro DM (2015) A change for the better? Digital health technologies and changing food consumption behaviors. Psychol Mark 32, 585-600.

27. Pellegrini CA, Pfammatter AF, Conroy DE et al. (2015) Smartphone applications to support weight loss: current perspectives. Adv Health Care Technol 1, 13-22.

28. Thomson CA \& Ravia J (2011) A systematic review of behavioral interventions to promote intake of fruit and vegetables. J Am Diet Assoc 111, 1523-1535.

29. Haapala I, Barengo NC, Biggs S et al. (2009) Weight loss by mobile phone: a 1-year effectiveness study. Public Health Nutr 12, 2382-2391.

30. Mehran L, Nazeri P, Delshad H et al. (2012) Does a text messaging intervention improve knowledge, attitudes and practice regarding iodine deficiency and iodized salt consumption? Public Health Nutr 15, 2320-2325.

31. Anderson M (2015) Technology Device Ownership: 2015. Washington, DC: Pew Research Center.

32. Dey AK, Wac K, Ferreira D et al. (2011) Getting closer: an empirical investigation of the proximity of user to their smart phones. In Proceedings of the 13th International Conference on Ubiquitous Computing, Beijing, China, 17-21 September 2011, pp. 163-172. New York: Association for Computing Machinery.

33. Handel MJ (2011) mHealth (mobile health) - using apps for health and wellness. Explore (NY) 7, 256-261.

34. Lieffers J, Vance V \& Hanning R (2014) Use of mobile device applications in Canadian dietetic practice. Can J Diet Pract Res 75, 41-47.

35. Boyce B (2014) Nutrition apps: opportunities to guide patients and grow your career. J Acad Nutr Diet 114, $13-15$.
36. Jospe MR, Fairbairn KA, Green P et al. (2015) Diet app use by sports dietitians: a survey in five countries. JMIR Mhealth Uhealth 3, e7.

37. Ball K, Mouchacca J \& Jackson M (2014) The feasibility and appeal of mobile 'apps' for supporting healthy food purchasing and consumption among socioeconomically disadvantaged women: a pilot study. Health Promot J Aust 25, 79-82.

38. Coughlin SS, Whitehead M, Sheats JQ et al. (2015) Smartphone applications for promoting healthy diet and nutrition: a literature review. Jacobs J Food Nutr 2, 021.

39. DiFilippo KN, Huang W-H, Andrade JE et al. (2015) The use of mobile apps to improve nutrition outcomes: a systematic literature review. J Telemed Telecare 21, 243-253.

40. Gilliland J, Sadler R, Clark A et al. (2015) Using a smartphone application to promote healthy dietary behaviours and local food consumption. BioMed Res Int 2015 , 841368.

41. Stawarz K, Cox AL \& Blandford A (2015) Beyond selftracking and reminders: designing smartphone apps that support habit formation. In Proceedings of the 33rd Annual ACM Conference on Human Factors in Computing Systems, Seoul, Republic of Korea, 18-23 April 2015, pp. 2653-2662. New York: Association for Computing Machinery.

42. Glanz K \& Bishop DB (2010) The role of behavioral science theory in development and implementation of public health interventions. Annu Rev Public Health 31, 399-418.

43. Pagoto S, Schneider K, Jojic M et al. (2013) Evidence-based strategies in weight-loss mobile apps. Am J Prev Med $\mathbf{4 5}$, 576-582.

44. Wearing J, Nollen N, Befort C et al. (2014) iPhone app adherence to expert-recommended guidelines for pediatric obesity prevention. Child Obes 10, 132-144.

45. West JH, Hall PC, Hanson CL et al. (2012) There's an app for that: content analysis of paid health and fitness apps. J Med Internet Res 14, e72.

46. Chang T-R, Kaasinen E \& Kaipainen K (2012) What influences users' decisions to take apps into use?: a framework for evaluating persuasive and engaging design in mobile apps for well-being. In Proceedings of the 11th International Conference on Mobile and Ubiquitous Multimedia, Ulm, Germany, 4-6 December 2012, article no. 2. New York: Association for Computing Machinery.

47. Hingle M \& Patrick H (2016) There are thousands of apps for that: navigating mobile technology for nutrition education and behavior. J Nutr Educ Behav 48, 213-218, e1.

48. Morrison LG (2015) Theory-based strategies for enhancing the impact and usage of digital health behaviour change interventions: a review. Digital Health 1, doi: https://doi. org/10.1177/2055207615595335

49. Wang Q, Egelandsdal B, Amdam GV et al. (2016) Diet and physical activity apps: perceived effectiveness by app users. IMIR Mhealth Uhealth 4, e33.

50. Nicholas J, Larsen EM, Proudfoot J et al. (2015) Mobile apps for bipolar disorder: a systematic review of features and content quality. J Med Internet Res 17, e198.

51. Reynoldson C, Stones C, Allsop M et al. (2014) Assessing the quality and usability of smartphone apps for pain selfmanagement. Pain Med 15, 898-909.

52. Breton ER, Fuemmeler BF \& Abroms LC (2011) Weight loss - there is an app for that! But does it adhere to evidenceinformed practices? Transl Behav Med 1, 523-529.

53. Taki S, Campbell KJ, Russell CG et al. (2015) Infant feeding websites and apps: a systematic assessment of quality and content. Interact J Med Res $\mathbf{4}$, e18.

54. Aitken M \& Lyle J (2015) Patient Adoption of mHealth: Use, Evidence and Remaining Barriers to Mainstream Acceptance. Parsippany, NJ: IMS Institute for Healthcare Informatics.

55. App Annie (2016) App Annie Index: Market Q1 2016. San Francisco, CA: App Annie. 
56. Department of Health \& Health Service Executive (2012) Your Guide to Healthy Eating Using the Food Pyramid. Dublin: Department of Health and Health Service Executive.

57. Department of Health (2016) Healthy Food for Life. The Food Pyramid Guide to Every Day Food Choices for Adults, Teenagers and Children Aged Five and Over. Dublin: Department of Health.

58. Michie S, Richardson M, Johnston M et al. (2013) The behavior change technique taxonomy (v1) of 93 hierarchically clustered techniques: building an international consensus for the reporting of behavior change interventions. Ann Behav Med 46, 81-95.

59. Lyons EJ, Lewis ZH, Mayrsohn BG et al. (2014) Behavior change techniques implemented in electronic lifestyle activity monitors: a systematic content analysis. J Med Internet Res 16, e192.

60. Stoyanov SR, Hides L, Kavanagh DJ et al. (2015) Mobile app rating scale: a new tool for assessing the quality of health mobile apps. JMIR Mhealth Uhealth 3, e27.

61. Tavakol M \& Dennick R (2011) Making sense of Cronbach's alpha. Int J Med Educ 2, 53-55.

62. Hayes AF \& Krippendorff K (2007) Answering the call for a standard reliability measure for coding data. Commun Methods Meas 1, 77-89.

63. Forman J \& Damschroder L (2008) Qualitative content analysis. In Empirical Research for Bioethics: A Primer, pp. 39-62 [L Jacoby and LA Siminoff, editors]. Oxford: Elsevier Publishing.

64. Latham GP \& Brown TC (2006) The effect of learning vs. outcome goals on self-efficacy, satisfaction and performance in an MBA program. Appl Psychol 55, 606-623.

65. Zimmerman BJ \& Kitsantas A (1997) Developmental phases in self-regulation: shifting from process goals to outcome goals. J Educ Psychol 89, 29-36.

66. Bardus M, van Beurden SB, Smith JR et al. (2016) A review and content analysis of engagement, functionality, aesthetics, information quality, and change techniques in the most popular commercial apps for weight management. Int J Behav Nutr Phys Act 13, 35.

67. Burrows TL, Khambalia AZ, Perry R et al. (2015) Great 'appeal' but not there yet: a review of iPhone nutrition applications relevant to child weight management. Nutr Diet 72, 363-367.

68. Chen J, Cade JE \& Allman-Farinelli M (2015) The most popular smartphone apps for weight loss: a quality assessment. JMIR Mhealth Uhealth 3, e104.

69. Direito A, Dale LP, Shields E et al. (2014) Do physical activity and dietary smartphone applications incorporate evidence-based behaviour change techniques? BMC Public Health 14, 646.
70. Zahry NR, Cheng Y \& Peng W (2016) Content analysis of diet-related mobile apps: a self-regulation perspective. Health Commun 31, 1301-1310.

71. Azar KMJ, Lesser LI, Laing BY et al. (2013) Mobile applications for weight management: theory-based content analysis. Am J Prev Med 45, 583-589.

72. Webb LT, Joseph J, Yardley L et al. (2010) Using the internet to promote health behavior change: a systematic review and meta-analysis of the impact of theoretical basis, use of behavior change techniques, and mode of delivery on efficacy. J Med Internet Res 12, e4.

73. Franco ZR, Fallaize R, Lovegrove AJ et al. (2016) Popular nutrition-related mobile apps: a feature assessment. JMIR Mhealth Uhealth 4, e85.

74. Lieffers JRL, Haresign H, Mehling C et al. (2017) The website-based eaTracker ${ }^{\circledR}$ 'My Goals' feature: a qualitative evaluation. Public Health Nutr 20, 859-869.

75. Con D \& De Cruz P (2016) Mobile phone apps for inflammatory bowel disease self-management: a systematic assessment of content and tools. JMIR Mhealth Whealth 4, e13.

76. Blecker T \& Abdelkaf N (2006) Complexity and variety in mass customization systems: analysis and recommendations. Manage Dec 44, 908-929.

77. Piller F, Schubert P, Koch M et al. (2005) Overcoming mass confusion: collaborative customer co-design in online communities. J Comput Mediat Commun 10, doi: 10.1111/ j.1083-6101.2005.tb00271.x

78. Chang C-C \& Chen H-Y (2009) I want products my own way, but which way? The effects of different product categories and cues on customer responses to web-based customizations. Cyberpsychol Behav 12, 7-14.

79. Sigala M (2006) Mass customisation implementation models and customer value in mobile phones services: preliminary findings from Greece. Manag Service Qual 16, 395-420.

80. Lee YJ \& Ha S (2016) Consumer use of the internet for health management. J Consum Health Internet 20, doi: http://dx.doi.org/10.1080/15398285.2015.1127114

81. Yardley L, Morrison L, Bradbury K et al. (2015) The personbased approach to intervention development: application to digital health-related behavior change interventions. $J$ Med Internet Res 17, e30.

82. Dunford E, Trevena H, Goodsell C et al. (2014) FoodSwitch: a mobile phone app to enable consumers to make healthier food choices and crowdsourcing of national food composition data. JMIR Mhealth Uhealth 2, e37. 